The University of Maine

\title{
DigitalCommons@UMaine
}

Psychology Faculty Scholarship

Psychology

6-1998

\section{Phonological Translation in Bilingual and Monolingual Children}

D. Kimbrough Oller

University of Memphis

Alan Cobo-Lewis

University of Maine - Main, alanc@maine.edu

Rebecca E. Eilers

University of Maine - Main, rebecca.eilers@umit.maine.edu

Follow this and additional works at: https://digitalcommons.library.umaine.edu/psy_facpub

Part of the Psychology Commons

\section{Repository Citation}

Oller, D. Kimbrough; Cobo-Lewis, Alan; and Eilers, Rebecca E., "Phonological Translation in Bilingual and Monolingual Children" (1998). Psychology Faculty Scholarship. 8.

https://digitalcommons.library.umaine.edu/psy_facpub/8

This Article is brought to you for free and open access by DigitalCommons@UMaine. It has been accepted for inclusion in Psychology Faculty Scholarship by an authorized administrator of DigitalCommons@UMaine. For more information, please contact um.library.technical.services@maine.edu. 


\title{
Phonological translation in bilingual and monolingual children
}

\author{
D. KIMBROUGH OLLER, ALAN B. COBO-LEWIS, and \\ REBECCA E. EILERS \\ University of Maine
}

\section{ADDRESS FOR CORRESPONDENCE}

D. Kimbrough Oller, University of Maine, Department of Communication Sciences and Disorders, LS N. Stevens Hall, Orono, ME 04469

\begin{abstract}
Bilingual children face a variety of challenges that their monolingual peers do not. For instance, switching between languages requires the phonological translation of proper names, a skill that requires mapping the phonemic units of one language onto the phonemic units of the other. Proficiency of phonological awareness has been linked to reading success, but little information is available about phonological awareness across multiple phonologies. Furthermore, the relationship between this kind of phonological awareness and reading has never been addressed. The current study investigated phonological translation using a task designed to measure children's ability to map one phonological system onto another. A total of 425 kindergarten and second grade monolingual and bilingual students were evaluated. The results suggest that monolinguals generally performed poorly. Bilinguals translated real names more accurately than fictitious names, in both directions. Correlations between phonological translation and measures of reading ability were moderate, but reliable. Phonological translation is proposed as a tool with which to evaluate phonological awareness through the perspective of children who live with two languages and two attendant phonemic systems.
\end{abstract}

In recent years, research in the acquisition of literacy has emphasized certain skills that are viewed as foundational - necessary, if not sufficient, conditions for the emergence of reading capability. Among these skills is one known as phonological awareness, which is the ability to take notice of phonemic units consciously. The presence of phonological awareness is often tested by verifying the ability to perform rhyming, syllable or phoneme counting, segmentation (pronouncing individual phonemic units from a presented syllabic string), elision (deleting a specified phonemic unit from a presented string), or blending (pronouncing a syllabic string composed of phonemic units presented individually).

Productive reading (i.e., decoding previously unseen words in alphabetical writing systems) necessitates the retrieval of grapheme-to-phoneme correspondences (Liberman, 1983). An alternative reading strategy is "whole word" reading, which involves the recognition and memory of the overall shapes of individual words, bypassing the necessity of decoding individual graphemes. Whole 
word reading may be possible in early stages of literacy acquisition, but seems to become increasingly cumbersome as reading vocabulary grows. At some point, learners may be obliged to adopt a productive strategy - one based not on the memorization of shapes, but on the recognition of correspondences between a small, fixed number of graphemic elements and a similarly small, fixed number of phonemes.

Emphasis on the importance of reading through the decoding of alphabetic elements has inspired a broad area of research on reading. The results of such research have indicated that the reading abilities of young children are positively correlated with their abilities to perform in tasks typically used to assess phonological awareness (Bradley \& Bryant, 1983, 1985; Byme, Freebody, \& Gates, 1992; Jorm, Share, MacLean, \& Matthews, 1984; Juel, Griffith, \& Gough, 1986; Vellutino \& Scanlon, 1987; Wagner \& Torgeson, 1987). But the nature of the relationship between success on phonological awareness tasks and reading remains elusive. While some might infer that phonological awareness plays a causal role in reading acquisition (Mattingly, 1980), the correlational nature of the relationship does not preclude the opposite direction of causality - that reading acquisition produces phonological awareness (Ehri, 1989). It is also possible that instead there is a mutual relationship by which reading and phonological awareness support one another and grow hand in hand (Tunmer \& Rohl, 1991).

One of the difficulties in differentiating empirically among the possible causal connections between phonological awareness and reading is that the capability for phonological awareness appears to be removed in varying degrees from the tasks that are used to assess it. For example, the awareness of phonemic units (which are, by definition, abstractions) is often tested in segmentation tasks that require the pronunciation of isolated chunks of sound that presumably correspond in some important way to abstract phonemic units, but are clearly not those units. Moreover, the required pronunciations of isolated units are artificial (especially in the case of consonants) because they are not naturally produced in isolation. In the case of stop consonants (a type common to all the world's languages), isolated pronunciation requires the addition of at least one short, vowel-like element (whether voiced or voiceless), an obvious intruder that complicates the correspondence between the presumed awareness of the phoneme and the action that is presumed to illustrate that awareness. It seems distinctly possible that a person might have a substantial awareness of phonemic units without having the ability to perform well in a segmentation task that requires the generation of artificial pronunciations.

Given that there is an indirect relationship between the concept of phonological awareness and the tasks that are used to assess it, it may be important to take stock of a variety of tasks that may provide additional perspective. The blind men who first touched the elephant, one on the leg and one on the tail, were both correct when one found the elephant to be like a tree and the other like a rope. Similarly, phonological awareness may have features that can only be noticed when we converge upon it from a variety of directions. One such direction is suggested by the fact that bilingual children must learn to use two systems of phonemic units. Indeed, recent work has suggested that the bilingual 
experience may affect phonological awareness in interesting ways (Bruck \& Genesee, 1995; Rubin \& Turner, 1989).

We have been struck by the ability of bilingual speakers to perform a task that may yield a new take on phonological awareness. The task, called phonological translation, has been evaluated in several previous studies whose purpose was to assess the fundamental characteristics of bilingualism (Ervin-Tripp, 1974; Flege \& Hammond, 1982; Flege \& Munro, 1994; Zuengler, 1985); the possible relationship between phonological awareness and reading ability was not the primary interest. The task requires a phonemically ordered rendering of a word from one language to another, thus forming a new, cognate-like phonological entity. An instructive example of phonological translation is seen in the borrowing or importation of proper names. The various pronunciations in English of Mao Tse Tung, for example, are all phonological translations from the Chinese version, which is similar to the anglicizations in some ways, but clearly different in others. The anglicizations are translations, in that they constitute phonemic sequences that correspond in an orderly fashion to a phonemic sequence of Chinese.

The person who originally formulates a phonological translation must tacitly or consciously generate a cross-language correspondence, either at a phonemic level or at a higher level of phonological structure, such as the syllable or phonological foot. Translations could also operate at a combination of levels of phonological structure: sometimes phonemically, sometimes syllabically, and so on. Foreign names that are used frequently in a language may, in the course of usage, come to have a fixed translational form that speakers of the language know by memory. Speakers may hear a name in their own language frequently enough so that it attains the status of a lexical item. When a speaker translates a name lexically, utilizing memorized forms, it is hard to gauge the extent to which phonological matching across languages has been performed.

We are particularly interested in instances of phonological translation that are based not on the memorization of linguistically borrowed forms, but on the creative, productive translation of words from one language into another (i.e., words or names not previously encountered in translated form). Creative translations are presumably required when one encounters foreign phonological material for which lexicalized translation alternatives are not available. In our work, we differentiate between real names that have fixed, translational forms and fictitious, made-up names that have to be translated entirely by phonological matching. Of course, children may or may not be aware of the fixed translations for individual real names, so in some cases real names may be translated entirely by phonological matching as well.

Our goal in this work is to evaluate the differences between monolingual and bilingual speakers in their abilities to perform phonological translation. Of course, creative phonological translations can be produced by any speaker, whether or not the speaker knows the language of origin for the word to be translated. Even monolingual individuals who hear words of a foreign language can generate native language sequences bearing a phonological resemblance to the foreign ones. In our limited informal experience, we have observed that 
monolingual adults are quite capable of translating short names (at least up to three syllables) from a foreign language to the native one, even when the names are fictitious. They have more difficulty translating in the opposite direction, a process characterized by long hesitations, multiple attempts, less confidence, and less success. The problems of translating from a native language to a foreign one may occur because monolinguals (a) have limited perceptual knowledge of the phonemic system of the foreign language, (b) have little or no command of pronunciation in the foreign language, (c) are uncertain about the appropriate correspondences between the phonemes of the two systems, or (d) experience some combination of all three.

Competent adult bilinguals seem to be more prepared for phonological translation, and they perform phonological translation more fluidly, perhaps owing to a greater command over the production, perception, and/or phonological correspondences in the two languages. Bilingualism requires that one leam to perform phonological translation in both directions with consummate ease. The translation of words or phrases can be performed frivolously or comically, as when a speaker mocks a "bad accent," but in other cases, translation is merely a routine function of communication for bilinguals. At the very least, the names of important people in the lives of bilingual individuals have to be spoken in both languages. One cannot reasonably avoid referring to one's business associates or family members in one language simply because their names originate in another, even if it is awkward (and sometimes seems pretentious) to switch in midstream from one phonological system to another. Bilinguals often provide a bridge for monolinguals, teaching them appropriate translations for names and other borrowings.

Bilingual children appear to grow up with phonological translation as a daily activity. Typically they are required to tell their parents and siblings about people (perhaps teachers or friends) whose names come from a different language or, likewise, to tell their teachers and friends about their parents and siblings. These circumstances produce a consistent requirement for the translation of phonological material - a need that may form the basis for a special sensitivity to phonological units and to the possibilities of forming correspondences between phonological materials of differing systems. While the capability for phonological translation must be developed, there is considerable unclarity about how such development occurs, given the lack of empirical study of phonological translation in young children. We do not know, at what age this ability begins to emerge, and the issue is complicated by the fact that many bilingual children begin to learn a second language after the first has already been established. Roles for experience in a second language and bilingual balance in phonological translation have not been previously studied.

Still, at every point on the continuum from monolinguality to bilinguality, competent mature speakers must engage in some type of phonological translation, at least to the extent that they are able to understand foreign-accented speech in their native language and to recognize and understand speech from widely differing dialects. It is an empirical question as to how much one gains in accuracy of phonological translation by practice and how much these gains may affect phonological awareness in a more general sense. It seems likely that 
bilinguals are more practiced in many of the acts of phonological translation than are monolinguals; it seems certain that they are more practiced in bidirectional translation. The special activity associated with translating in two directions may yield special benefit for the bilingual child in terms of understanding phonemics or other phonological properties; it might even form the basis for special capabilities in the acquisition of alphabetical reading skills.

We hasten to acknowledge that the phonological matching required in phonological translation is different from that of productive reading, where the correspondences needed are grapheme-to-phoneme rather than phoneme-to-phoneme. Still, we are intrigued by the thought that phonological translation might foster or enhance a special kind of phonological awareness. The performer of translation establishes correspondences between the phonemic elements (or elements at a higher level of rhythmic structure) of one language and those of another. Having succeeded in that task, it might then be a smaller step to form similar correspondences between either phonemic system and a written alphabet. If so, perhaps a bilingual child would have a special advantage in leaming to read.

We have been immersed in research on bilingualism. The goals of the research are general, encompassing theoretical interests in the nature of language acquisition, the possible interdependence of languages in the minds of bilinguals (Cummins, 1985), the relationship of spoken language knowledge to knowledge in other modalities (especially as seen in reading), and a variety of practical matters regarding the particular effects of bilingualism on children in both academic and more general intellectual domains. The broad, programmatic effort in which we have been engaged has gained a momentum on which we have capitalized in our studies of phonological translation. The populations of children are drawn from a broader study, which was conceived and implemented in part due to the special advantages of conducting such research in Dade County, Florida.

Dade County is a location where about half the populace is Hispanic and about half the school children have significant knowledge of both English and Spanish. It is a unique community in the United States because of the high prestige associated here with Spanish. Unlike Hispanic bilingual populations in other parts of the United States, the whole range of socioeconomic levels is found in substantial proportions among the Miami Latin community, which includes particularly strong financial and political components. Cuban Americans, who make up over $60 \%$ of the Miami Hispanic population, control large sectors of the banking industry, media, and government. In particular, the main strata of Hispanic society in Miami compare favorably in income and educational opportunity with mainstream America (Boswell \& Curtis, 1983; Pérez, 1986), while they have retained the use of the Spanish language to a greater degree than Latin groups of different national origins (Nielsen \& Fernández, 1982).

Dade County consists of a single very large school district (the fourth largest nationally), administered in a unified way by a long-standing board and encompassing all of metropolitan Miami as well as many outlying areas. Dade County is also the site of well-established (and much-studied) education programs adapted for bilingual students. Most elementary schools in Dade County educate children using an English immersion approach in which children with limited 
English proficiency are moved rapidly from substantial home language support in school to nearly English-only instruction, usually during kindergarten. Through the fifth grade, the typical pattern endeavors to maintain knowledge of the home language through a half-hour of daily instruction in the home language. We refer to such programs as Type 1 (T1). Type 2 (T2) programs comprise two elementary schools that educate children in Spanish for $40 \%$ of the day and in English for $60 \%$, a pattern that is maintained from kindergarten through the fifth grade. These T2 programs, each enrolling over 1,000 students, are essentially neighborhood-based, drawing $97 \%$ of their students from their own geographic boundaries. Since the schools are relatively representative of the social spectrum in Dade County, they offer an opportunity for subject selection in a way that may be controlled for socioeconomic status and other potentially relevant factors, such as how much English is present in the home.

Miami thus offers all the combinations of social class, language background, and educational programs necessary to evaluate the key factors expected to influence the academic success of bilingual children. Through an excellent and longstanding relationship with the Dade County Public Schools and through the use of the U.S. census database for each school catchment area in the district, it has been possible for us to select matched groups of monolingual and bilingual children. In our studies of phonological translation, the goal is to compare monolingual and bilingual children's abilities, sampling broadly from socioeconomic and language experience patterns. For all the children in the study, we seek to understand both their phonological translation abilities and their reading knowledge in English; for the bilingual children, we are interested in the same information in Spanish.

\section{METHODS}

\section{Subjects}

A total of 425 children were selected from kindergarten and second grade programs for normally developing children at ten sites in Dade County. Parents were sent a questionnaire, which they were asked to fill out and return if they were interested in having their children participate in the study. Those who wished to participate were required to respond to a variety of demographic questions, on the basis of which subject selection and assignment to subgroups was subsequently performed by the staff of the project.

The 66 monolingual English-speaking kindergartners who were selected, along with the 46 monolingual second graders, mostly came from four schools where the dominant language was English and at least half the students were non-Hispanic and living in English-only homes. The remainder of the monolingual students $(<20 \%)$ came from $\mathrm{Tl}$ schools. The 180 bilingual (Spanish/English) kindergartners and 134 bilingual second graders came from six schools with $90 \%$ or more Hispanic students (two schools implemented T2 programs and four schools implemented Tl programs).

The students were subcategorized in terms of socioeconomic status (SES) and 
language spoken at home. During the selection process, $52 \%$ of the monolinguals and $47 \%$ of the bilinguals were deemed high SES, as determined by parental responses on the questionnaire. High-SES families had at least some college education (an average of 15 years of formal education), owned their own home, were fully employed in white-collar professions and/or businesses, and had annual incomes over $\$ 40,000$ (usually much over). Low-SES families had education levels of high school or less (an average of 11 years, including vocational schooling), usually did not own their homes, were employed in blue-collar or labor positions or were unemployed, and had annual incomes less than $\$ 30,000$ (an average of $\$ 10,000$ ).

Among the bilinguai subjects we selected, $43 \%$ had roughly equal exposure to English and Spanish in the home, and 57\% were exposed only to Spanish at home. Bilingual children whose parents indicated "mostly English," "mostly Spanish," or "only English" on the questionnaire were not selected. The bilingual children who were deemed second language learners had leamed Spanish first and were acquiring English in school. However, many of the children in the group with English and Spanish at home could be viewed as simultaneous learners of English and Spanish. Based on a variety of data from the project (e.g., Eilers, 1997), it can be said that, in spite of their considerable exposure to Spanish, the bilingual children as a whole tended to show a preference for speaking English to each other from at least the first grade, even though many of them had experienced little English at home. Other data (Cobo-Lewis \& Umbel, 1997; Umbel \& Cobo-Lewis, 1997) have suggested that bilingual children are more literate in English than in Spanish by the second grade. Consequently, although many of the children had relatively balanced exposure to English and Spanish at home, it appears that balanced bilingualism was not often the result. Among the bilingual children, $48 \%$ were in $\mathrm{Tl}$ schools.

\section{Materials and procedure}

Because one of the most easily recognized and ubiquitous forms of phonological translation is found in the importation of proper names, we chose to focus on common proper names in English and Spanish. The particular names chosen would provide a sampling of the special phonetic units from each language. The children were first trained to perform phonological translation using four real names: for example, for English, Nancy, Arnold, Betty, and David; for Spanish, Rosario, Jorge, Octavio, and Berta. After the training, the children were presented with five evaluation items: for English, Freddy, Victor, Jennifer, Donald, and Dorothy; for Spanish, Maria, Rafael, Alicia, Orlando, and Teresa. It should be noted that in Miami it is impossible to go to public school without hearing some Spanish every day, whether one is monolingual or bilingual. All the names included among the evaluation items in both languages were specifically chosen because they are common among children in Miami.

After the presentation of real names, children were presented with five fictitious names to translate; this task was used to test their ability to perform creative, novel phonological translations: for English, Rasky, Themon (rhymes with 
"demon"), Sparner, Gasil (rhymes with "Basil"), and Murdy (rhymes with "dirty"); for Spanish, Parasco, Marol, Ortaña, Cherro, and Edalfo. The names were chosen to represent well-formed phonotactic sequences in each language and to provide an opportunity for the children to translate a substantial number of phonetic elements that are language-specific in both cases. Of particular interest were the English-specific consonants $t h[\theta]$, as in "Themon"; $r[\mathrm{I}]$, as in "Rasky" and "Victor"; and dark $l[t]$ as in "Gasil." Spanish-specific consonants included both the tapped [ $r$ ] and trilled $r[\mathrm{r}$ ], as in "Rafael" and "Parasco"; the tense unaspirated stop, as in "Parasco" and "Ortaña"; and the light postvocalic $l[1]$, as in "Edalfo" and "Rafael."

Each child was seated in a quiet room with one of the eight experimenters, who had been selected for employment in the research because they were balanced Spanish/English bilinguals with excellent pronunciation in both languages. The phonological translation task was one of many tests administered to the children; this one occurred in the fifth testing session, so students were already well-accustomed to individual testing. The elicitation of phonological translations was accomplished quite effectively by all the testers. Half the children were randomly assigned to do the task in English first (translating from English to Spanish), and half were assigned to do the task in Spanish first (translating from Spanish to English). The experimenters were assigned to test sessions on a counterbalanced basis to the extent that this was possible, given the scheduling constraints of schools, children, and testers.

The experimenters were trained to administer the protocol, including an initial explanation to the child in which they would say (e.g., in the English to Spanish translation): "We're going to play a game now. First I say a name in English, and then you say the same name in Spanish. It'll be like this. I say 'Peter' ([phirəs]) and you say [piter]. I say 'Emily' ([Eməti]) and you say [emili]. OK, now let's try it." The experimenter then presented the child with four training items to translate from English to Spanish, encouraging the child to try the translation, praising the child if the effort was successful, and providing hints if the child did not understand the task. All the models were presented orally, and the responses were oral. Orthographic representations were neither indicated nor solicited. In each case of training, the experimenter provided the child with a model of perfect phonological translation after the child's attempts, along with praise for the effort. At the end of the training session, regardless of the child's level of success, the evaluation was conducted with the test items, and no further feedback was given other than encouragement to proceed. Instructions for both the Spanish to English and English to Spanish segments were provided in English for the monolingual subjects. The bilingual subjects received instructions in Spanish for the Spanish to English segment and in English for the English to Spanish segment. The testing was organized in such a way that the Spanish to English and English to Spanish translation work occurred in the same session. However, a separate task of syntax judgments was always interpolated between the two phonological translation segments; it was hoped that the break would prevent the children from losing interest in the task. The total time required for translation training and testing was 5 to 10 minutes per child. 


\section{Scoring}

The experimenters were taught to score the children's translations using a very simple method: they were given a checklist. If the child failed to translate at all (i.e., pronounced the target name in the same way as the experimenter), the experimenters marked "no translation" for the item in question. Another option was "perfect translation." We made a substantial effort as a group of experimenters and phoneticians to designate the range of acceptable "perfect" pronunciations for each item. For example, translating from Spanish to English, "Rafael" [rafael] could be translated correctly in quite a number of ways, the most common of which is [ıæfiet]. However, the first vowel could be rendered correctly as either [Iafiet] or [Iafiet], and the second vowel could be rendered correctly as either [ræfaet] or [ræfeet]. By recombining the three correct vowels in each position, subjects could produce nine correct translations of "Rafael." We insisted that each element in the English (translated) version had to have a distinctly English quality. In particular, we insisted that the $\mathrm{N} / \mathrm{be}$ dark (velarized [ $\mathrm{f}]$ ) and the / $\mathrm{r} /$ be retroflexed [ $\mathrm{I}$, as it is in American English. We also accepted "Ralph," a lexical translation of the name Rafael, as a "perfect translation," but only if it was pronounced without accent. Intermediate pronunciations in which the phonetic elements of Spanish and English were mixed (e.g., [rafiet], where some elements are translated and others are not) were given an intermediate score. Failures to attempt a translation and exact repetitions of the target items were scored as zeros.

Translating from English to Spanish, "Victor" [viktor] could be rendered correctly as [biktor] or [viktor]. It is important to note that there are fewer options in translating from English to Spanish. This is a general pattern: translating into English offers more correct options than translating into Spanish, presumably because the phonemic inventory of English is much larger than that of Spanish. Consequently the possible mappings from Spanish to English tend to be one to many, whereas from English to Spanish, they tend to be many to one. In the example of "Victor," the two renderings of English [v] in Spanish are not phonemically distinct, but are dialectal variants of the same Spanish phoneme, /v/. On the other hand, the various vocalic renderings of "Rafael" in English are mostly based on phonemically different English vowels.

The scores were indicated as 0 (no translation or no attempt), 1 (intermediate translation), or 2 (perfect translation) for each item. (This method constitutes only a preliminary effort at scoring the phonological translations. Subsequent methods are planned to incorporate fine phonetic transcriptions and acoustic analysis.) Each child's session produced a series of scores. The overall score was based on 20 items, 10 English to Spanish and 10 Spanish to English. In each group half consisted of real names, and half consisted of fictitious names.

To determine the reliability of the phonological translation scoring, measures were taken from the audiotape recordings that had been made during the test sessions.' Fifteen recordings were selected at random and rescored, based only on information from the audiotape recordings. The rescorings were done by a different individual than the tester on the tape. The average discrepancy between 
live-scored and audiotape-scored tests (based on 20 test items) was less than $10 \%$. The scores arrived at by the different observers correlated at 0.70 . Because intertester reliability was not as high as we would have liked, the statistical power of our evaluations of group differences may have been limited. However, the design controlled against potential bias associated with differences among the testers by scrambling the assignment of testers with regard to the child subgroupings.

\section{Other tests}

In addition, the children were tested on a variety of English and Spanish standardized evaluations. These included most of the subtests from the WoodcockJohnson batteries of oral language and reading (Woodcock, 1981 a, 1981b, 1982; Woodcock \& Johnson, 1977) in both English and Spanish and the English and Spanish Peabody Picture Vocabulary Tests (Dunn \& Dunn, 1981; Dunn, Padilla, Lugo, \& Dunn, 1986). These tests were administered so that the order of testing in Spanish and English was counterbalanced across groups. The present article focuses on the Woodcock-Johnson Basic Reading measure and the Peabody Picture Vocabulary Test in addition to the phonological translation measures.

\section{Design and analysis}

Although the factors of school type (T1 or T2), SES (high or low), and language spoken at home (only Spanish or both Spanish and English) were of great interest in other aspects of the broader study, they were not the primary focus here. In order to preserve power for the testing of a priori hypotheses, school type, SES, and language spoken at home were analyzed for descriptive purposes only. The a priori intentions were to compare the performances of bilingual and monolingual children in the translation of real and fictitious names and in the direction of translation (English to Spanish or Spanish to English). These comparisons were made via a split-plot analysis of variance; a between-subjects factor, number of languages, coded monolingual versus bilingual subjects, and two within-subjects factors coded translation type: the two levels of translation direction were English to Spanish and Spanish to English, and the two levels of name type were real name and fictitious name. These three factors were combined to form a total of seven main effects and interactions, and Bonferroni corrections were applied so that the groupwise Type I error rate across these effects would be .05 . The analysis statistically controlled for the effects of, and interactions with, grade (kindergarten vs. second), SES (low vs. high), language spoken at home (Spanish only vs. Spanish and English), and school type (T1 vs. T2). As the last two factors only applied to bilingual children, they were nested within the factor, number of languages. All of these additional variables will be assessed in other studies from the broader effort, but it can be mentioned in anticipation that, even without Bonferroni corrections, the effects of school type, SES, and language spoken at home were in each case small and nonreliable. However, the grade effect was large and clearly reliable, although age effects constituted only a background issue in the present research. The strong grade effect suggests 
that the phonological translation measure, even with limited intertester scoring reliability, provides a workable assessment of a developing skill. Because the design was slightly unbalanced, sums of squares for a target effect were evaluated only after all effects of the same or lower order were partialed out (e.g., Cohen \& Cohen, 1983).

Subsequent multiple regression analyses assessed the correlations between the translation of fictitious names (the crucial test of creative phonological translation) and the measures of reading and verbal ability. In these analyses, a phonological translation score for fictitious names was the dependent variable. First, the effect of child's age as a linear predictor was partialed out. Then, for the bilinguals, the effect of school type was partialed out. Finally, we examined the partial correlations of the phonological translation score with the WoodcockJohnson Broad Reading measure and the Peabody Picture Vocabulary Test (for the bilinguals, we examined the partial correlations for both the English and Spanish versions of these tests).

\section{Hypotheses}

In the analysis of variance, two main effects were anticipated. First, bilingual speakers were expected to perform better in overall phonological translation than monolinguals, based on their greater experience in performing such translations. Second, the translation of real names was expected to be easier than the translation of fictitious names for both groups, since real name translation might be based on memorized lexical relationships whereas fictitious name translation would require creative, on-line work. We also anticipated a Name Type $\times$ Number of Languages interaction. It was expected that the differential performance between real and fictitious names would be attenuated in the bilinguals. The bilinguals would presumably perform well in translation independent of memory and consequently would perform about as well with fictitious as with real names. The monolinguals, on the other hand, were expected to perform relatively well in the case of recognized names with presumably remembered translations, but much less well in the case of unfamiliar (fictitious) names. Finally, a Number of Languages $\times$ Translation Direction interaction was anticipated. Monolinguals were expected to perform better when translating into English than into Spanish (since they did not necessarily know how to pronounce in Spanish), while bilinguals were expected to show no such imbalance (because they were selected on the basis of their ability to speak both languages well).

\section{RESULTS}

\section{Group means}

Figure 1 shows the pattern of overall averaged scores for all subjects by grade level, and Figure 2 pools across grade level. The results of the research confirmed the first hypothesis: bilingual children (unweighted $M=0.82$ ) performed better in phonological translation than did the monolingual children (unweighted $M=0.48$ ), as revealed by a main effect of number of languages, $F(1,405)=$ 


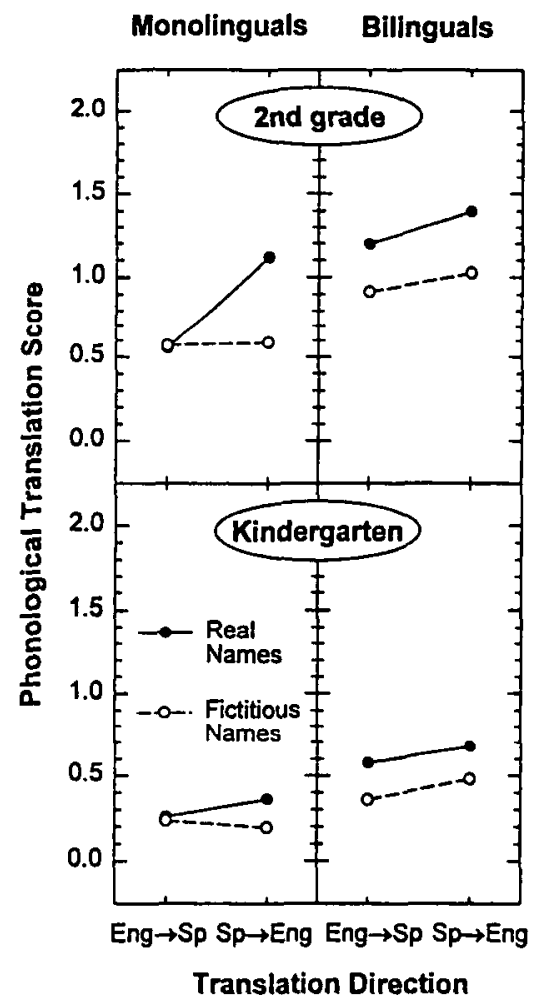

Figure 1. Unweighted means of phonological translation score by grade level, number of languages (monolingual vs. bilingual), translation direction, and name type (real vs. fictitious).

45.74, groupwise $p<10^{-9}$. The second hypothesis was also confirmed; although smaller in absolute difference between conditions, it was even more reliable. Real names were translated with much greater facility (unweighted $M=0.77$ ) than were fictitious names (unweighted $M=0.55$ ), $F(1,405)=223.95$, groupwise, $p<10^{-39}$. Unexpectedly, there was also a main effect of translation direction, with both groups showing better translation from Spanish to English (unweighted $M=0.73$ ) than from English to Spanish (unweighted $M=0.58$ ), $F(1,405)=46.54$, groupwise $p<10^{-9}$.

The statistically reliable interactions were unanticipated, but yield an interesting story. Although there was a two-way interaction of Translation Direction $x$ Name Type, $F(1,405)=8.45$, groupwise $p<.03$, it is more profitably interpreted with reference to the significant three-way interaction of Number of Languages $\times$ Translation Direction $\times$ Name Type, $F(1,405)=25.26$, groupwise $p<$ $10^{-5}$. Post-hoc tests conducted to follow up on the three-way interaction revealed that the simple two-way interaction of Translation Direction $\times$ Name Type was significant for the monolinguals, $F(1,108)=45.87, p<10^{-10}$, but not for the bilinguals, $F(1,386)=0.02, p>.88$. Figure 2 displays the means underlying the 


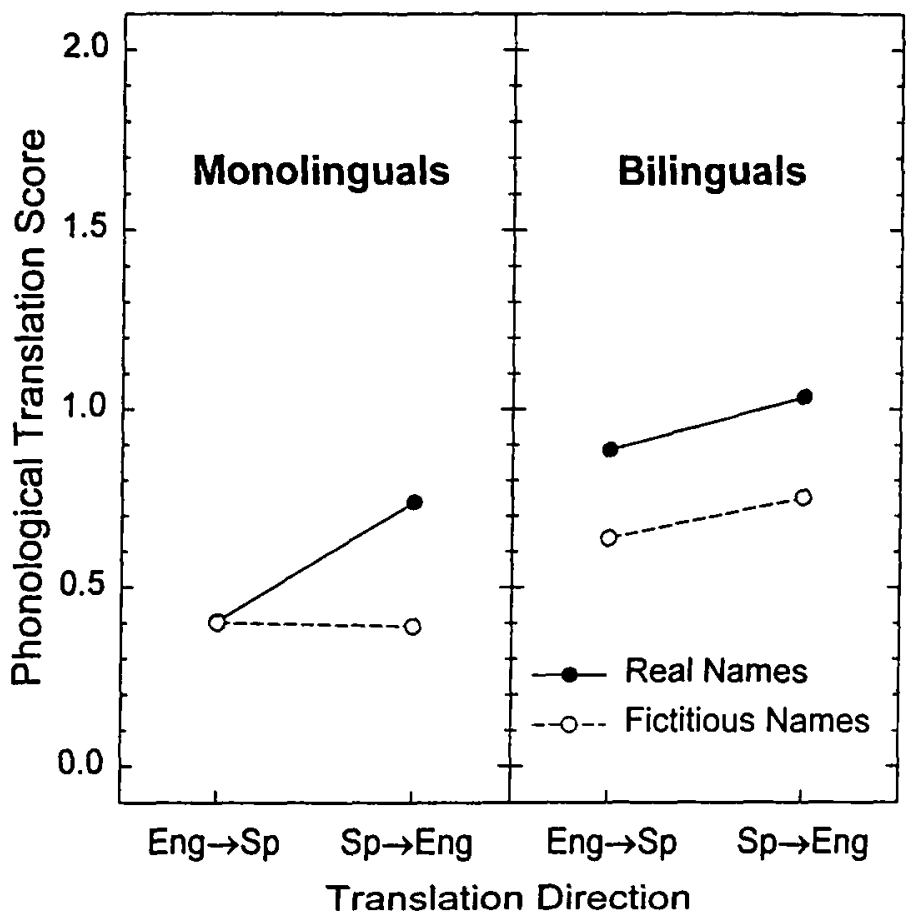

Figure 2. Unweighted means of phonological translation score by number of languages, translation direction, and name type.

three-way interaction. The monolingual speakers performed uniformly poorly for real names translated from English to Spanish (unweighted $M=0.41$ ), fictitious names translated from English to Spanish (unweighted $M=0.40$ ), and fictitious names translated from Spanish to English (unweighted $M=0.39$ ); they only showed better performance in translating real names from Spanish to English (unweighted $M=0.74$ ). This was verified by examining the pairwise differences among the monolingual scores, which were significant (groupwise $p s$ $\left\langle 10^{-7}\right.$ ) for the comparisons between real names from Spanish to English and the other three scores, but were not significant (groupwise $p s>.99$ ) for the comparisons among the other three monolingual scores. In contrast, the bilingual speakers showed a large advantage for real (unweighted $M=0.96$ ) over fictitious (unweighted $M=0.69$ ) translations, as confirmed by the simple main effect of name type, $F(1,386)=179.65, p<10^{-34}$, but no simple interaction of Name Type $\times$ Translation Direction.

The predicted two-way interaction of Number of Languages $\times$ Name Type was not statistically reliable after Bonferroni correction, $F(1,405)=6.22$, groupwise $p<.09$. The predicted interaction of Number of Languages $\times$ Translation Direction was also not reliable, $F(1,405)=0.007$, groupwise $p>.99$. As it turned out, both groups showed a substantial advantage in translating from 
Table 1. Partial correlations of phonological translation ( fictitious names only) with reading and verbal measures

\begin{tabular}{lll}
\hline & Kindergarten & Second grade \\
\hline $\begin{array}{l}\text { Monolingual English } \\
\text { Basic reading }\end{array}$ & .17 & .18 \\
$\quad$ Vocabulary & .11 & .10 \\
$\begin{array}{l}\text { Bilinguals in English } \\
\text { Basic reading }\end{array}$ & $.25^{* *}$ & $.33^{* * *}$ \\
$\quad$ Vocabulary & .16 & .17 \\
Bilinguals in Spanish & & \\
$\quad$ Basic reading & $.22^{*}$ & $.40^{* * * *}$ \\
Vocabulary & $.26^{* *}$ & $.33^{* * *}$ \\
\hline \hline
\end{tabular}

${ }^{*} p<.05 ;{ }^{* *} p<.005 ;{ }^{* * *} p<.001 ;{ }^{* * * *} p<.001$

Spanish to English (see Figure 2). The effect was even strong for the bilinguals, as confirmed by the simple main effect of translation direction, $F(1,386)=$ $33.95, p<10^{-8}$. For the monolinguals, the effect was only present for real names. Only in the case of real name translations did the monolingual speakers show a reliably greater difference between directions of translation than did the bilinguals; the simple interaction of Translation Direction $\times$ Number of Languages for real names was significant, $F(1,405)=8.79, p<.005$.

Although a grade effect was not a focus here, it is clear that second graders greatly outperformed kindergartners. Additional analysis indicates that perfect translation occurred much more often among the second graders (94\% gave at least one perfect translation on the test items) than among the kindergartners $(59 \%)$. The average proportion of perfect translations for the second graders was $37 \%$, while for the kindergartners it was only $12 \%$. The average proportion of zero scores was $67 \%$ for the kindergartners, but only $34 \%$ for the second graders.

\section{Partial correlations}

The pattem of results on real versus fictitious names across monolingual and bilingual speakers provided a basis for selecting results on fictitious names for the correlational analysis. Our reasoning was that, since the translation of fictitious names appears to reflect more of an active mental process, the search for ways to predict reading ability should focus on the translation of fictitious rather than real names.

Table 1 presents the partial correlations of the fictitious translations (between English and Spanish) with the Woodcock-Johnson Basic Reading measure and the Peabody Picture Vocabulary Test. For the monolingual children, the mean for both translation directions was correlated with the English reading and vocabulary measures. For the bilingual children, the mean for both translation directions was correlated with the English reading and vocabulary scores and 
with the Spanish scores. The very highest of these partial correlations with the reading measure was only .40 , and the partial correlation with the receptive vocabulary measure in Spanish was not much lower (.33). There is a suggestion that, for bilinguals in English, the partial correlations with the reading measure may be higher than those with the vocabulary measure. However, this pattern is questionable for bilinguals in Spanish. Although some partial correlations were statistically reliable, none were dramatically high.

\section{DISCUSSION}

The present research indicates that the phonological translation abilities for proper names can be tested reliably in kindergartners and second graders, both monolingual and bilingual. As expected, the bilingual children were better at phonological translation than were the monolingual children. The pattern of performance is instructive. The translation of real names seem to be performed more accurately than the translation of fictitious ones, presumably because real names are recognized and their translated forms, which are commonly produced in the community of speakers, are remembered and retrieved during the performance of the translation task. On the other hand, listeners do not possess remembered phonological representations for fictitious names and thus cannot use lexical memory to support the translation task. The greater knowledge in the case of the real names, then, supports their better translation.

Because of the discrepancy between the translation of real names and that of fictitious names, it seems clear that only the translations of fictitious names reflect an active matching of the phonological elements from one language to the other. The monolinguals in kindergarten and second grade showed little evidence that they engaged in any such matching in the present study. They performed at low levels when translating fictitious names in both directions (Spanish to English and English to Spanish) and when translating real names from English to Spanish. Only when real names were translated from Spanish to English did their scores show improvement, suggesting that their performance was based heavily on memory and the recall of lexicalized name translations rather than on active processes of cross-language phonological matching. Of course, some phonetic recognition of Spanish names had to be involved, or else the subjects would not have known how to choose a particular anglicized name on each trial; but this phonetic recognition could have proceeded through a passive mechanism.

The bilingual children, in contrast, showed genuine phonological matching abilities; their translation of fictitious names was moderately good in both language directions. However, it should be emphasized that the bilingual children appeared to translate utilizing both active phonological matching and lexically memorized forms, as evidenced by the fact that their real name translations were consistently better than their fictitious ones.

Unexpectedly, we found that the bilingual children performed better in Spanish to English translation than the reverse. Because they were selected for bilingualism and, if anything, might have been expected to show a bias toward Spanish (about half the children were exposed only to Spanish at home according to 
parent questionnaire data), it was surprising to see them present a pattern of performance suggesting a possible English bias. Such a bias is one of the possible reasons for the pattern; this possibility is supported by data on the children's frequency of usage of the two languages (Eilers, 1997). In classrooms and in hallways, the bilingual children as a whole tended to speak more English than Spanish when speaking to each other (as indicated by the samples taken in an aspect of the broader study); they spoke Spanish preferentially only when speaking to teachers during periods when Spanish was the designated language of instruction (which generally occurred only in $\mathrm{T} 2$ schools). The bias toward better translation into English brings to mind the widely reported tendency of second language learners to translate words faster and more accurately from L2 to L1 than from L1 to L2 (see, e.g., Kroll, 1993). This tendency has been interpreted to indicate that speakers find it easier to retrieve vocabulary from memory in their $\mathrm{L} 1$ than in their L2. It is difficult to see how English could be viewed as the $\mathrm{Ll}$ for the bilingual children in the present study. In particular, the children from Spanish-only homes seemed to have the reverse arrangement - that is, English as the L2. Thus, the surprising tendency of the bilingual children to prefer to speak their L2 hints at a very rapid change: it appears that Spanish is being replaced by English as the language in which the children possess the greatest facility.

There is, however, another possibility that cannot be ruled out without further evidence. The tendency to translate better from Spanish to English might be due to inherent phonemic or phonetic differences between the two languages. English has a larger phonemic inventory than Spanish, both in consonants and in vowels. Generally, English is thought to have 11 phonemic vowels as well as diphthongs, whereas Spanish is analyzed to possess a five-vowel system and a few diphthongs. In addition, English has substantial allophonic variation for both vowels and consonants. Translating from Spanish to English may yield more possible correct options for a particular Spanish vowel in terms of English phonemes and their various allophonic forms than the reverse case. Of course, the likelihood of hitting any one of the correct options may be relatively low, but the sum of the probabilities of hitting any of the various correct possibilities may be high. When translating in the opposite direction, the flexibility may be more limited; in general, each English phonemic unit must be translated to exactly one correct Spanish phoneme, and consequently the task may be inherently more difficult. This scenario represents only one of several possible ways in which the differences between Spanish and English phonological systems might engender imbalances in the ease of translation in one direction or the other. Another possibility is that the translation direction differences are associated with differences in orthographic knowledge in (and relative orthographic difficulties of the two languages. At present, we are simply uncertain about the reasons for the translation direction effect found in the present study.

We are ultimately interested in phonological translation, both as a fundamental phenomenon of language performance and as a potential indicator of emerging phonological awareness and/or reading abilities. In this context, we sought correlational evidence of a tie between phonological translation and reading skills. Although we did find such a tie, the expected differential relationship of 
phonological translation to reading over vocabulary was rather equivocal. This is somewhat surprising, given that phonological translation (especially for fictitious names) has been shown to provide an intriguing measure of children's abilities to match phonemic or phonological elements across languages. Three categories of explanation for this weakness are considered.

First, the phonological translation task utilized here represents an early attempt to formulate a measure. The ten items of fictitious name translation may not have been sufficient to yield an adequately stable indication of the children's translation abilities. In such a short list, the phonemic inventories of the two languages cannot be fully represented. Furthermore, the methods we used to score the translation attempts could be usefully refined. The success of such refinements would depend on the careful definition of correct and incorrect translation attempts and on the training of experimenters to a high level of reliability. It is also possible that the measures of reading we used were not adequate, especially at the kindergarten level where letter-word recognition and word attack scores were low simply because the children were just beginning to read.

A second possible reason for the low correlations between phonological translation and reading concerns the age of the children studied and the fact that comparisons were made concurtently. Many of the children were still reading at a relatively rudimentary level, even in the second grade. Their phonological translation scores remained far below ceiling levels, although these might improve substantially within a year or two of development. In subsequent work, it will be possible to assess correlations at the fifth grade level and beyond, based on extensions of the work now in progress. While the present work assessed concurrent correlations, longitudinal research would enable researchers to assess the correlation of phonological translation skills at early ages with reading skills at later ages. It is possible that phonological translation would predict later reading better than it predicts concurrent reading skills.

The third reason to consider is the most interesting, even though it is also the most speculative. Let us assume for the sake of argument that the correlations are low not because of measurement inadequacy, but because phonological translation does not in fact predict reading skills well. A task such as phoneme elision appears to yield a much higher correlation with written word identification in second grade than does phonological translation. For example, Wagner, Torgesen, and Rashotte (1994) reported a .65 zero-order correlation between elision and Woodcock-Johnson written word identification in second grade. In our own data, however, when we correlated the second-graders' phonological translation of fictitious names with the same portion of the Woodcock-Johnson battery, the correlation never exceeded .38 , regardless of translation direction. Since the present work indicates that phonological translation in bilingual children does reflect some aspect of phonological awareness, why would the correlation to reading be low to moderate? Logically we would have to conclude that not all aspects of phonological awareness predict reading well - or at least not much better than they predict receptive vocabulary. Perhaps phoneme elision or other traditional tasks thought to reflect phonological awareness reflect those aspects that most naturally correspond to reading, while a more general phonological awareness, which is also reflected in phonological translation, is more 
loosely connected to reading skills. In other words, there may be more to phonological awareness than is reflected in its relationship to reading. It may turn out that measures of phonological translation will predict aspects of language development that are involved in reading, but are not unique to it.

Traditional tasks such as elision, segmentation, and blending might more neatly reflect reading skills because they are commonly trained in reading instruction. This possibility cannot be entirely explained away by the evidence that some phonological awareness tasks have yielded stable individual differences (Byme et al., 1992; Wagner, Torgeson, Laughon, Simmons, \& Rashotte, 1993), and that training in phonological awareness tasks by themselves has produced little benefit for subsequent reading achievement (Crowder \& Wagner, 1991). It may be that the children who possess a stable talent for performing well in reading are the same ones who possess a stable talent for performing well on phonological awareness tasks. The connection may be the result of an inherent and fundamental relationship between reading and tasks such as elision. Yet it is important to remember that, even if there is an inherent tie between the ability to perform well in phoneme elision and in reading and even if phoneme elision is in some way related to the abstract notion of phonological awareness, it does not necessarily follow that the general construct of phonological awareness is responsible for reading progress.

The path from deep phonological awareness to reading may be a tortuous one. The deep skill may have a number of facets and may influence reading in multiple, indirect ways. Different tasks thought to reflect the nature of deep phonological awareness may be confounded, both by the steps they require to reach the depths and by the direction from which they approach them. Phonological translation is a tool with which to evaluate phonological awareness through the perspective of children who possess two languages and two attendant phonemic systems. In spite of the relatively low correlations obtained in this first effort, we remain committed to finding better ways of assessing phonological translation and of tapping into the special phonological awareness of bilingual children - an awareness that could foster special reading capabilities. Our goals as we continue this effort include extending our studies upward in age, as well as comparing phonological translation abilities with the ability to perform traditional tasks that have been treated as measures of phonological awareness.

\section{ACKNOWLEDGMENT}

This research has been supported by NIH/NICHD grant \# 5R0I HD30762 to D. Kimbrough Oller. Thanks go to the Dade County Schools for their assistance in this work.

\section{NOTE}

1. Recordings were made whenever possible in the hope of eventually performing transcriptions for all the sessions. However, recorders were not always available, and the cost of fine phonetic transcription of all the tapes has thus far been prohibitive. When utilized in the study, the miniature tape recorder (about the size of a textbook) was placed unobtrusively on the worktable between the child and the experimenter. 
Oller et al.: Phonological translation

\section{REFERENCES}

Boswell, T. D., \& Curtis, J. R. (1983). The Cuban American experience: Culture, images and perspectives. Totowa, NJ: Rowman \& Allanheld.

Bradley, L., \& Bryant, P. (1983). Categorising sounds and learning to read: A causal connexion. Nature, 301, 419-421.

(1985). Rhyme and reason in reading and spelling. Ann Arbor: University of Michigan Press.

Bruck, M., \& Genesee, F. (1995). Phonological awareness in young second language learners. Journal of Child Language, 22, 307-324.

Byrne, B., Freebody, P., \& Gates, A. (1992). Longitudinal data on the relations of word-reading strategies to comprehension, reading time, and phonemic awareness. Reading Research Quarterly, 27, $|4|-151$.

Cohen, J., \& Cohen, P. (1983). Applied multiple regression/correlation analysis for the behavioral sciences (2nd ed.). Hillsdale, NJ: Erlbaum.

Cobo-Lewis, A. B., \& Umbel. V. M. (1997). Language and literacy in bilingual children: Comparisons among monolinguals and bilinguals in standardized assessments of English proficiency. Poster presented at the Society for Research in Child Development. Washington, DC.

Crowder, R. G., \& Wagner, R. K. (1991). The psychology of reading: An introduction. New York: Oxford University Press.

Cummins, J. (1985). Bilingualism and special education: Issues in assessment and pedagogy. San Diego, CA: College-Hill Press.

Dunn, L., \& Dunn, L. (1981). Peabody Picture Vocabulary Test-Revised. Circle Pines, MN: American Guidance Service.

Dunn, L., Padilla, E., Lugo, D., \& Dunn, L. (1986). Test de Vocabulario en Imágenes Peabody Adaptación Hispanoamericana [Peabody Picture Vocabulary Test - Latin American adaptation]. Circle Pines, MN: American Guidance Service.

Ehri, L. C. (1989). The development of spelling knowledge and its role in reading acquisition and reading disability. Joumal of Learning Disabilities, 22. 356-365.

Eilers, R. E. (1997). Language and literacy in bilingual children: Deep description of language usage in one-way and two-way schools. Poster symposium at the Society for Research in Child Development, Washington, DC.

Ervin-Tripp, S. M. (1974). Is second language learning like the first? TESOL Quarterly, 8, 111-125.

Flege, J., \& Hammond, R. (1982). Mimicry of nondistinctive phonetic differences between language varieties. Studies in Second Language Acquisition, 5, 1-17.

Flege, J., \& Munro, M. (1994). The word unit in L2 speech production and perception. Studies in Second Language Acquisition, 26, 381-411.

Jorm, A., Share, D., MacLean, R., \& Matthews, R. (1984). Phonological similarity effects, memory span and developmental reading disorders. Applied Psycholinguistics, 5, 201-207.

Juel, C., Griffith, P., \& Gough, P. (1986). Acquisition of literacy: A longitudinal study of children in first and second grade. Journal of Educational Psychology, 78, 243-255.

Kroll, J. (1993). Accessing conceptual representation for words in a second language. In R. Schreuder \& B. Weltens (Eds.), The bilingual lexicon (pp. 83-114). Amsterdam: John Benjamins.

Liberman, I. Y. (1983). A language-oriented view of reading and its disabilities. In H. Myklebust (Ed.), Progress in learning disabilities (Vol. 5, pp. 81-101). New York: Grune \& Stratton.

Mittingly, I. G. (1980). Reading, linguistic awareness, and language acquisition. Haskins Laboratories Status Report on Speech Research, SR-61, 135-150.

Nielsen, F., \& Femández, R. M. (1982). Achievement of Hispanic students in American high schools: Background characteristics and achievement. Washington, DC: U.S. Government Printing Office.

Pérez, L. (1986). Cubans in the United States. Annals of the American Academy of Political and Social Sciences, 487, 126-137.

Rubin, H., \& Turner, A. (1989). Linguistic awareness skills in grade one children in a French immersion setting. Reading and Writing: An Interdisciplinary Journal, I, 73-86.

Tunmer, W. E., \& Rohl, M. (1989). Phonological awareness and reading acquisition. In D. Sawyer \& B. Fox (Eds.), Phonological awareness in reading: The evolution of current perspectives (pp. 1-30). New York: Springer-Verlag.

Umbel, V. M., \& Cobo-Lewis, A. B. (1997). Language and literacy in bilingual children: Perfor- 
Oller et al.: Phonological translation

mance of bilingual children in standardized tests of English-and Spanish-language proficiency. Poster presented at the Society for Research in Child development, Washington, DC.

Vellutino, F., \& Scanlon, D. M. (1987). Phonological coding, phonological awareness, and reading ability: Evidence from longitudinal and experimental study. Merrill-Palmer Quarterly, 33, 321-364.

Wagner, R. K., \& Torgesen, J. K. (1987). The nature of phonological processing and its causal role in the acquisition of reading skills. Psychological Bulletin, 101, 192-212.

Wagner, R. K., Torgesen, J. K., Laughon, P., Simmons, K., \& Rashotte, C. A. (1993). Development of young readers' phonological processing abilities. Journal of Educational Psychology, 85, 83-103.

Wagner, R. K., Torgesen, J. K., \& Rashotte, C. A. (1994). Development of reading-related phonological processing abilities: New evidence of bidirectional causality from a latent variable longitudinal study. Developmental Psychology, 30, 73-87.

Woodcock, R. W. (1981a). Woodcock Language Proficiency Battery. Riverside, CA: DLM Teaching Resources.

(1981b). Woodcock Language Proficiency Battery-Spanish Form. Riverside, CA: DLM Teaching Resources.

(1982). Batería Woodcock Psico-educativa en Español. Riverside, CA: DLM Teaching Resources. Woodcock, R. W., \& Johnson, M. B. (1977). Woodcock-Johnson Psycho-Educational Battery. Riverside, CA: DLM Teaching Resources.

Zuengler, J. (1985). Identity markers in L2 pronunciation. Studies in Second Language Acquisition, $10,33-39$. 